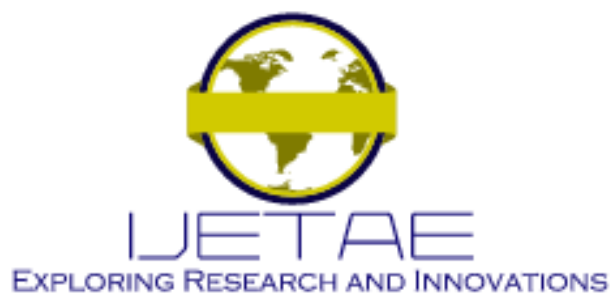

International Journal of Emerging Technology and Advanced Engineering

Website: www.ijetae.com (E-ISSN 2250-2459, Scopus Indexed, ISO 9001:2008 Certified Journal, Volume 11, Issue 09, September 2021)

Manuscript Received: 07 August 2021, Received in Revised form: 05 September 2021, Accepted: 12 September 2021

DOI: 10.46338/ijetae0921_01

\title{
Decision Support Model for Evaluating the Performance of Tutor's Teaching using Moodle
}

\author{
Mira Aryani ${ }^{1}$, Ditdit Nugeraha Utama ${ }^{2}$ \\ Computer Science Department, BINUS Graduate Program - Master of Computer Science, Bina Nusantara University, Jakarta, \\ Indonesia 11480 \\ E-mail: ${ }^{1}$ mira.aryani@binus.ac.id, ${ }^{2}$ ditdit.utama@binus.edu
}

\begin{abstract}
Tutors as online teachers assume a significant part in the achievement of learning success. The capacity of an actual tutor is to instruct and work responsibly according to the learning objectives. The main goal of this research is to propose a decision support model (DSM) which is worked for tutor performance evaluation. Fuzzy AHP and hill climbing are the main method operated scientifically in this study, which both are utilized to analyse, design, and develop the constructed model. By utilizing log information on the Moodle platform, a study can be conducted, where the measurement of tutor performance is selected as the object of research using eleven parameters; like assignment feedback, assignment score, discussion feedback, discussion score, participation, motivation, teaching style, communication, concern, approach, and critical thinking. Later, such a model is going to be a problem solver in helping decision makers in deciding a decision to upgrade the tutors.
\end{abstract}

Keywords - Tutor Performance, Fuzzy AHP, Hill Climbing, Decision Support Model, Moodle

\section{INTRODUCTION}

Tutors as online teachers play an important role in the success of learning that implements the open and distance learning systems. This learning system has proven effective to increase the reach and equalization in quality of higher education opportunities for all Indonesian citizens, including the people who live in remote areas, through archipelago, and in various parts of the world [1].

The function of the tutor is to represent teaching, work responsibly to meet the objectives of the institution [2], to minimize supervision of online teaching tutors, and to evaluate performance of the tutor [3]. Based on the criteria above, an assessment of the tutor can be made. By this, many scientists have practically conducted research with decision support model (DSM) as the main issue.

The study which related to the assessment model of lecturers to overcome difficulties in determining bonus assessment will use the Fuzzy logic method [4].
Fuzzy DSM for performance assessment is applied to calculate the performance bonus of lecturers in educational institutions. This model adopts two main types of methods. Fuzzy logic works in characterizing parameters and their behaviour based on fuzzy rules until the results are determined, and hill climbing (HC) to optimize the search process and results.

Other researchers have attributed DSM as a solution in continuing performance of logistics staff using the discrepancy evaluation model and the analytical hierarchy process (AHP) [5]. The model is built using the AHP to give weight in criteria and recommendations of policy decisions.

Furthermore, there is also a model to determine the best supplier using fuzzy AHP method to determine the subcriteria weight and fuzzy TOPSIS method to select the best supplier [6], as well as fuzzy MOLP method to calculate supplier quota allocation. The result of this study is fuzzy AHP method that produces the best sub-criteria.

The purpose of this paper is to identify and determine the performance assessment parameters for online teaching tutors on the Moodle platform, and build a model to support decisions of tutor performance assessment using fuzzy AHP and $\mathrm{HC}$ methods. By using 11 criteria in assessing where Moodle is already used by more than 200 countries in the world [7] and log data in the Moodle database with 50 tutors at Indonesia Open University [8], the assessment results can be beneficial for institutions in improving the tutor performance. The criteria which have been operated based on the needs of institutions, have been widely done by previous studies; such as [9], [10], [11], [12], [13], [14], and [15].

\section{LITERATURE REVIEW}

Some related studies such as [4] research that have raised the topic of performance assessment lecturers, use the fuzzy DSM. 


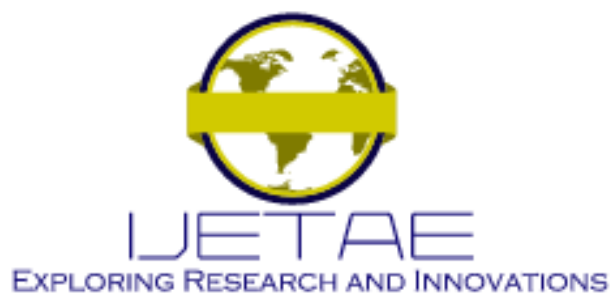

International Journal of Emerging Technology and Advanced Engineering

Website: www.ijetae.com (E-ISSN 2250-2459, Scopus Indexed, ISO 9001:2008 Certified Journal, Volume 11, Issue 09, September 2021)

The research has interviewed 35 respondents and four parameters as measurement, namely education, teaching ability, research, and community service. The parameter score that has been taken from the respondent's interview is processed to be a coefficient value (to prioritize parameters) through the fuzzy logic concept, and subsequently use $\mathrm{HC}$ method to optimize the final assessment then. The fuzzy logic in this study is managed to provide a bonus coefficient value for lecturers, and $\mathrm{HC}$ method used in optimizing the search process in finding the best performance.

The results of this study have revealed fuzzy logic's decision model that shows most economically profitable bids for tenders in construction work. The methods used are fuzzy logic and fuzzy cluster [4]. The approach uses a fuzzy DSM and proposes a new approach called the improvement process on student grades. This study shows that fuzzy systems can provide a better evaluation system than classical systems. However, improvements are still needed in terms of methods to reduce the error rate [15].

In using the discrepancy evaluation model (DEM) and AHP methods, DEM method is used to identify policy evaluation criteria, while AHP method is functioned to give weight to the criteria and recommendations of policy result. This research has not actually reached the final stage because further research will be done to improve the model, especially in determining of sub-criteria [5].

A method to determine sub-criteria is fuzzy logic based on Tsukamoto conception. It serves the avoidance obscurity of parameter value in person to make the decision. Based on the results which has been reached by the model tests, the optimal quantity of goods purchased in pharmaceutical companies can be proposed practically and efficiently. The results of the study refer to the application of fuzzy Tsukamoto in DSM. Based on the test results, it can be concluded that the fuzzy variable that used for input must be more than two variables, therefore it will produce better results when the variable is more complex. The results show the average error percentage is $0.5 \%$ [16].

The research explains the methods in determining the best suppliers by using the fuzzy AHP method to determine the sub-criteria weight, fuzzy TOPSIS method to select the best suppliers, as well as the fuzzy MOLP method to calculate supplier quota allocation. The result of the research shows that the fuzzy AHP method produces best sub-criteria. The results display fuzzy AHP manages to determine the weight of criteria and sub-criteria well [6].
The conclusion from several studies have shown that fuzzy AHP is proven to be effective and suitable in solving problems for decision maker, and $\mathrm{HC}$ is proven to be better for optimization.

\section{ReSEARCH Methodology}

The research stages as appeared in figure 1 are conducted through 4 (four) stages; (1) literature studies, (2) attribute selection, (3) model building, and (4) models evaluating that have been built for consistency. On literary study stage by Desk research method, there are references related to decision-making models that can be used. They are [4] the fuzzy logic and HC methods [17], the fuzzy logic and fuzzy cluster methods [15], the fuzzy methods [5], the DEM and AHP [16], and the Tsukamoto fuzzy logic, the fuzzy TOPSIS, and the fuzzy MOLP [6]. The research is related to the characteristics of good tutors for online learning [11], [13], [1], [10], and [12]. References of material are taken from journals, books, articles, internet, and thesis.

Based on literature studies, the knowledge gained is used for research development. In addition, any attributes that show the character of a good tutor are obtained, they tailored to the needs of this study. The data source used is data collected from the database on Moodle platform, and by conducting an interview with an expert judgment, as to the data owner for clarification and determining the attributes that will be used in this study. The selected attributes will be a basis to build the model. Before being used as the basis for model, we need to check consistency of the ratio to see if the comparison is good, the acceptable assessment results are those that have CR $<10 \%(0.1)$. The next step is to build the tutor performance assessment model using the fuzzy AHP method [6] for parameter weight assessment, and $\mathrm{HC} \mathrm{[4]} \mathrm{to} \mathrm{determine} \mathrm{the} \mathrm{final} \mathrm{value}$ of management decisions. This is necessary because one tutor can take care of more than 1 (one class), tutor nurtures 4 classes and produces different assessment parameters. To determine the results of its value are used the HC method that proved to be more effective.

\section{RESUlt AND Discussion}

The model built for tutor performance evaluation uses the fuzzy AHP method. Fuzzy AHP is an analytical method developed by traditional AHP. Fuzzy AHP is considered more suitable for explaining ambiguous decisions than traditional AHP. 


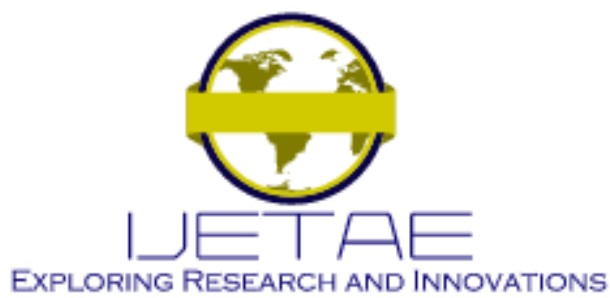

International Journal of Emerging Technology and Advanced Engineering

Website: www.ijetae.com (E-ISSN 2250-2459, Scopus Indexed, ISO 9001:2008 Certified Journal, Volume 11, Issue 09, September 2021)

It is a method that combines analytical hierarchy process methods and fuzzy theory that can be used to assess the performance of tutors who teach online using Moodle. The process flow of the model is depicted in Figure 2.

\section{A. Analytic Hierarchy Process and Consistency Testing}

There are 11 parameters used, namely, discussion feedback (K1), discussion score (K2), assignment feedback (K3), assignment score (K4), participation (K5), communication (K6), motivation (K7), teaching style (K8), approach (K9), critical thinking (K10), concern (K11).

The discussion feedback (K1) is taken from the average number of discussions that are given feedback by tutors, the discussion score (K2) is taken from the average number of discussions assessed by tutors. Assignment feedback (K3) is the average number of assignments given by tutors. Assignment score (K4) is the average number of assignments assessed by tutors.
Furthermore, the participation (K5) is the number of hits tutors. Communication (K6) is the average assessment of the questionnaire for communication by students. Motivation (K7) is the average assessment of the questionnaire for motivation by students. Teaching style (K8) is the average of the questionnaire assessment for teaching style by students. Approach (K9) is the average assessment of the questionnaire for the approach style by students. Critical thinking (K10) is the average assessment of the questionnaire for critical thinking by students. The final one, concern (K11) is the average assessment of the questionnaire for concern by students.

Next to determine the pairwise comparison matrix which can be seen in TABLE 1. Here, all parameters are compared to each other. The expert was involved to do so. The normalization process for comparison result is executed theoretically then, and the normalization result is able to be mentioned in TABLE 2 .

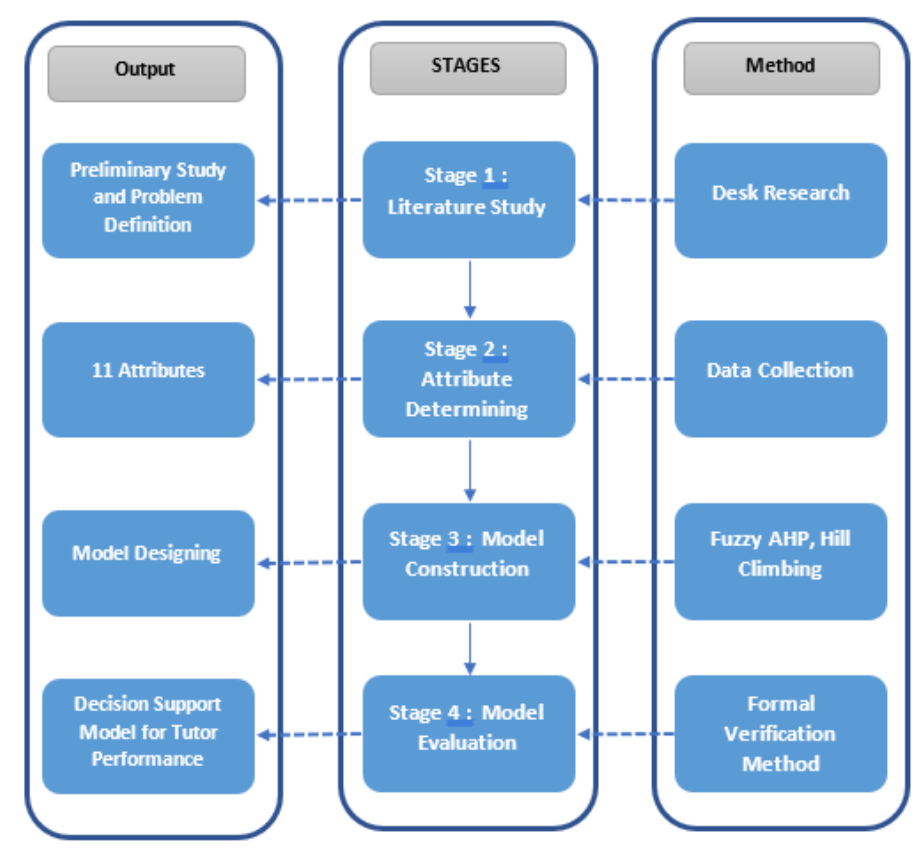

Figure 1: Research Stages 


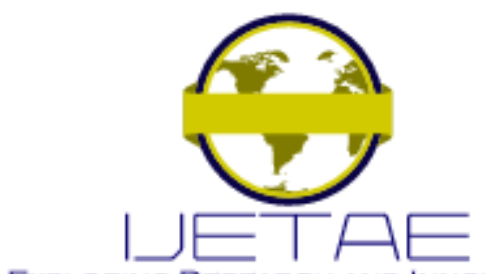

EXPLORING RESEARCH AND INNOVATIONS

International Journal of Emerging Technology and Advanced Engineering

Website: www.ijetae.com (E-ISSN 2250-2459, Scopus Indexed, ISO 9001:2008 Certified Journal, Volume 11, Issue 09, September 2021)

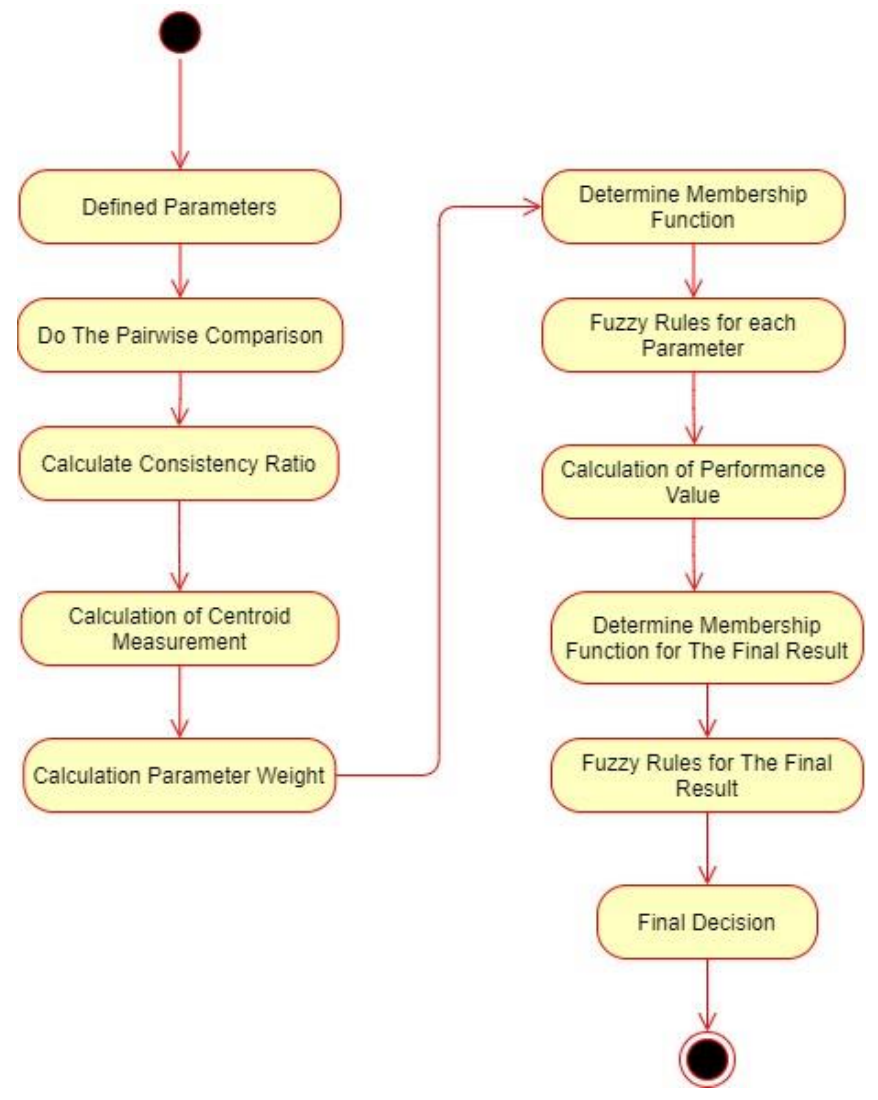

Figure 2: The Activity Diagram of the Constructed Model

TABLE 1:

PAIRWISE COMPARISON

\begin{tabular}{|l|c|c|c|c|c|c|c|c|c|c|c|}
\hline & K1 & K2 & K3 & K4 & K5 & K6 & K7 & K8 & K9 & K10 & K11 \\
\hline K1 & 1.00 & 0.33 & 1.00 & 0.33 & 0.33 & 1.00 & 3.00 & 3.00 & 1.00 & 1.00 & 0.33 \\
\hline K2 & 3.00 & 1.00 & 3.00 & 1.00 & 3.00 & 3.00 & 3.00 & 5.00 & 3.00 & 3.00 & 3.00 \\
\hline K3 & 1.00 & 0.33 & 1.00 & 0.33 & 0.33 & 1.00 & 3.00 & 3.00 & 1.00 & 1.00 & 0.33 \\
\hline K4 & 3.00 & 1.00 & 3.00 & 1.00 & 5.00 & 1.00 & 3.00 & 5.00 & 3.00 & 3.00 & 3.00 \\
\hline K5 & 3.00 & 0.33 & 3.00 & 0.20 & 1.00 & 1.00 & 3.00 & 1.00 & 1.00 & 3.00 & 0.33 \\
\hline K6 & 1.00 & 0.33 & 1.00 & 1.00 & 1.00 & 1.00 & 0.33 & 1.00 & 1.00 & 1.00 & 1.00 \\
\hline K7 & 0.33 & 0.33 & 0.33 & 0.33 & 0.33 & 3.00 & 1.00 & 1.00 & 1.00 & 1.00 & 1.00 \\
\hline K8 & 0.33 & 0.20 & 0.33 & 0.20 & 1.00 & 1.00 & 1.00 & 1.00 & 1.00 & 1.00 & 1.00 \\
\hline K9 & 1.00 & 0.33 & 1.00 & 0.33 & 1.00 & 1.00 & 1.00 & 1.00 & 1.00 & 3.00 & 1.00 \\
\hline K10 & 1.00 & 0.33 & 1.00 & 0.33 & 0.33 & 1.00 & 1.00 & 1.00 & 0.33 & 1.00 & 1.00 \\
\hline K11 & 3.00 & 0.33 & 3.00 & 0.33 & 3.00 & 1.00 & 1.00 & 1.00 & 1.00 & 1.00 & 1.00 \\
\hline
\end{tabular}




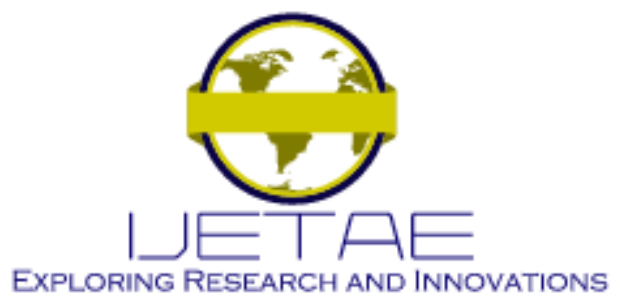

International Journal of Emerging Technology and Advanced Engineering

Website: www.ijetae.com (E-ISSN 2250-2459, Scopus Indexed, ISO 9001:2008 Certified Journal, Volume 11, Issue 09, September 2021)

TABLE 2:

NORMALIZATION RESULTS AND PRIORITY WEIGHT

\begin{tabular}{|c|c|c|c|c|c|c|c|c|c|c|c|c|}
\hline & K1 & K2 & K3 & K4 & K5 & K6 & K7 & K8 & K9 & K10 & K11 & PW \\
\hline K1 & 0.06 & 0.07 & 0.06 & 0.06 & 0.02 & 0.07 & 0.15 & 0.13 & 0.07 & 0.05 & 0.03 & 0.0687 \\
\hline K2 & 0.17 & 0.21 & 0.17 & 0.19 & 0.18 & 0.20 & 0.15 & 0.22 & 0.21 & 0.16 & 0.23 & 0.1890 \\
\hline K3 & 0.06 & 0.07 & 0.06 & 0.06 & 0.02 & 0.07 & 0.15 & 0.13 & 0.07 & 0.05 & 0.03 & 0.0687 \\
\hline K4 & 0.17 & 0.21 & 0.17 & 0.19 & 0.31 & 0.07 & 0.15 & 0.22 & 0.21 & 0.16 & 0.23 & 0.1880 \\
\hline K5 & 0.17 & 0.07 & 0.17 & 0.04 & 0.06 & 0.07 & 0.15 & 0.04 & 0.07 & 0.16 & 0.03 & 0.0925 \\
\hline K6 & 0.06 & 0.07 & 0.06 & 0.19 & 0.06 & 0.07 & 0.02 & 0.04 & 0.07 & 0.05 & 0.08 & 0.0686 \\
\hline K7 & 0.02 & 0.07 & 0.02 & 0.06 & 0.02 & 0.20 & 0.05 & 0.04 & 0.07 & 0.05 & 0.08 & 0.0617 \\
\hline K8 & 0.02 & 0.04 & 0.02 & 0.04 & 0.06 & 0.07 & 0.05 & 0.04 & 0.07 & 0.05 & 0.08 & 0.0487 \\
\hline K9 & 0.06 & 0.07 & 0.06 & 0.06 & 0.06 & 0.07 & 0.05 & 0.04 & 0.07 & 0.16 & 0.08 & 0.0698 \\
\hline K10 & 0.06 & 0.07 & 0.06 & 0.06 & 0.02 & 0.07 & 0.05 & 0.04 & 0.02 & 0.05 & 0.08 & 0.0523 \\
\hline K11 & 0.17 & 0.07 & 0.17 & 0.06 & 0.18 & 0.07 & 0.05 & 0.04 & 0.07 & 0.05 & 0.08 & 0.0920 \\
\hline
\end{tabular}

As mentioned before, after a paired comparison, the next step is normalization by summing the values of each column in the matrix (see TABLE 2). Then, divide each matrix entry by the total column of each, and sum the values contained in one row. Then calculated average matrix entries contained in a single row, and the result is expressed as a priority weight (PW).

To calculate consistency ratio (CR), the multiplication matrix operated, the results of comparison assessment have to be paired with matrix PW. Followed by the division between the matrix multiplication result value and PW value, the average value is symbolized by $\lambda_{\max }$ or can be referred as the maximum eigenvalue; where $\lambda_{\max }$ is used to calculate consistency index (CI) by using the equation (1). Furthermore, to calculate CR value with equation (2), the pairwise comparison is considered consistent if the CR value less than $0.1(\mathrm{CR} \leq 0.1)$.

$$
\begin{aligned}
& C I=\frac{X_{n \operatorname{nax} x}-n}{n-1} \\
& C R=\frac{C I}{n-R I}
\end{aligned}
$$

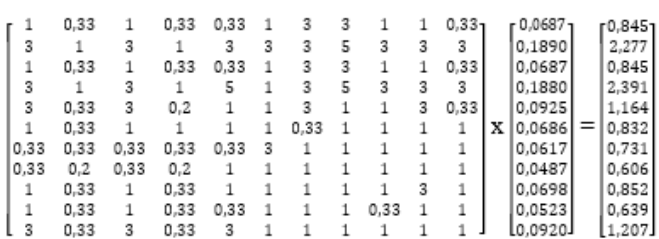

Based on the matrix, the result obtained $\lambda_{\max }$ value is 12.35. The CI value uses $\mathrm{n}=11$, because there are eleven parameters. Here, CI is 0.135. Then, CR calculation done with $n$ is 11 and RI is 1.51 . The CR value is gotten, it is 0.089. The pairwise comparison matrix for the 11 parameters is consistent because CR was measured and got less than 0.1 .

$$
\begin{aligned}
& C I=\frac{Z_{\max }-n}{n-1}=\frac{12.85-11}{11-1}=0.135 \\
& C R=\frac{C I}{R I}=\frac{0.135}{1.51}=0.089
\end{aligned}
$$

After the pairwise comparison was done in TABLE 1, then the value is converted to fuzzy scale. TABLE 3 shows the conversion of AHP scale to fuzzy scale. Here, the data shown only two parameters as examples ( $\mathrm{K} 1$ and $\mathrm{K} 11$ only). 


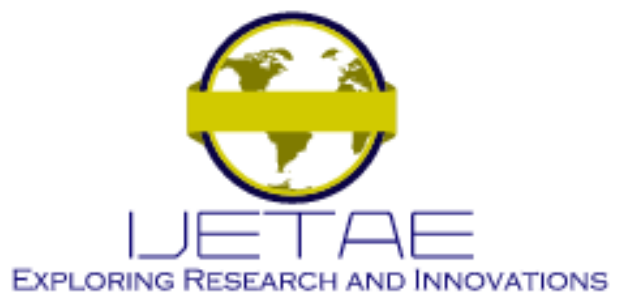

International Journal of Emerging Technology and Advanced Engineering

Website: www.ijetae.com (E-ISSN 2250-2459, Scopus Indexed, ISO 9001:2008 Certified Journal, Volume 11, Issue 09, September 2021)

TABLE 3:

CONVERT AHP SCALE TO FUZZY SCALE

\begin{tabular}{|c|c|c|c|c|c|c|c|}
\hline & \multicolumn{3}{|c|}{ K1 } & $\ldots$ & \multicolumn{3}{|c|}{ K11 } \\
\cline { 2 - 8 } & 1 & $\mathrm{~m}$ & $\mathrm{u}$ & $\ldots$ & 1 & $\mathrm{~m}$ & $\mathrm{u}$ \\
\hline $\mathrm{K} 1$ & 1 & 1 & 1 & $\ldots$ & 0.2 & 0.33 & 1 \\
\hline $\mathrm{K} 2$ & 1 & 3 & 5 & $\ldots$ & 1 & 3 & 5 \\
\hline K3 & 0.33 & 1 & 1 & $\ldots$ & 0.2 & 0.33 & 1 \\
\hline K4 & 1 & 3 & 5 & $\ldots$ & 1 & 3 & 5 \\
\hline K5 & 1 & 3 & 5 & $\ldots$ & 0.2 & 0.33 & 1 \\
\hline K6 & 0.33 & 1 & 1 & $\ldots$ & 1 & 1 & 3 \\
\hline K7 & 0.2 & 0.33 & 1 & $\ldots$ & 1 & 1 & 3 \\
\hline K8 & 0.2 & 0.33 & 1 & $\ldots$ & 1 & 1 & 3 \\
\hline K9 & 0.33 & 1 & 1 & $\ldots$ & 1 & 1 & 3 \\
\hline K10 & 0.33 & 1 & 1 & $\ldots$ & 1 & 1 & 3 \\
\hline K11 & 1 & 3 & 5 & $\ldots$ & 1 & 1 & 1 \\
\hline
\end{tabular}

TABLE 4:

CALCULATION OF EACH LINE $1, \mathrm{~m}, \mathrm{u}$

\begin{tabular}{|l|c|c|c|}
\hline Parameter & Lower & Middle & Upper \\
\hline K1 & 0,56 & 0,82 & 2 \\
\hline K2 & 1,11 & 2,57 & 4,25 \\
\hline K3 4 & 0,5 & 0,82 & 1,81 \\
\hline K5 & 1,1 & 2,7 & 3,79 \\
\hline K6 & 0,62 & 1,05 & 2,19 \\
\hline K7 & 0,5 & 0,82 & 1,49 \\
\hline K8 & 0,48 & 0,67 & 1,73 \\
\hline K9 & 1,1 & 0,61 & 1,1 \\
\hline K10 & 1,16 & 0,9 & 0,9 \\
\hline K11 & 0,45 & 1,1 & 1,55 \\
\hline$\Sigma$ Column & 8,76 & 12,73 & 21,92 \\
\hline
\end{tabular}

After the conversion done, then the next is to do the process of calculating centroid measurement. It can be seen in TABLE 4. TABLE 4 is the result of each line calculation for each parameter.

In the normalization process, the upper divisor value is used to divide the lower value and the lower divisor value is used to divide the upper value, while the middle divisor value is still using the middle value.
After obtaining the normal value for each parameter, the defuzzification process [18] is carried out with the equation (3); where this value will be the weight of the parameter. All parameters' weights are represented clearly in TABLE 5.

$$
C_{r}=\frac{1}{2}(a u+m+(1-a) l)
$$




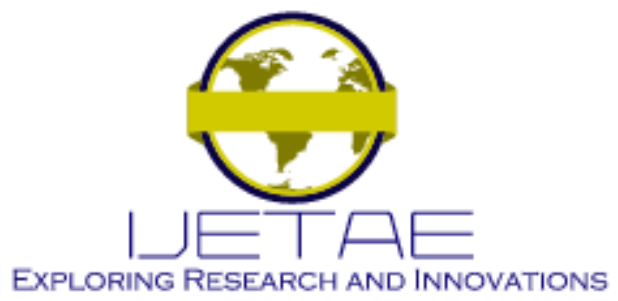

International Journal of Emerging Technology and Advanced Engineering

Website: www.ijetae.com (E-ISSN 2250-2459, Scopus Indexed, ISO 9001:2008 Certified Journal, Volume 11, Issue 09, September 2021)

TABLE 5: PARAMETER WEIGHTS

\begin{tabular}{|c|c|}
\hline Parameter & $\begin{array}{c}\text { Parameter } \\
\text { Weight }(\mathbf{W})\end{array}$ \\
\hline K1 & 0,095 \\
\hline K2 & 0,145 \\
\hline K3 & 0,0875 \\
\hline K4 & 0,225 \\
\hline K5 & 0,11 \\
\hline K6 & 0,0775 \\
\hline K7 & 0,08 \\
\hline K8 & 0,07 \\
\hline K9 & 0,0725 \\
\hline K10 & 0,07 \\
\hline K11 & 0,095 \\
\hline
\end{tabular}

\section{B. Membership Function}

For parameters, K1, K2, K3, and K4 have three variable linguistics namely Low, Medium, and High, while for parameters $\mathrm{K} 4, \mathrm{~K} 5, \mathrm{~K} 6, \mathrm{~K} 7, \mathrm{~K} 8, \mathrm{~K} 9, \mathrm{~K} 10$, and $\mathrm{K} 11$ have two linguistic variables namely Low and High. The membership function is depicted in Figures 3 to Figure 13.

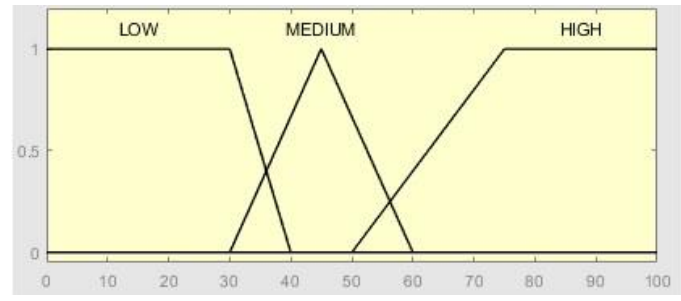

Figure 3: Membership Function for discussion feedback (K1)

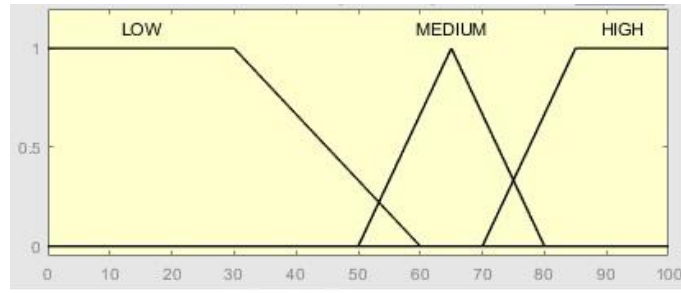

Figure 4: Membership Function for discussion score (K2)

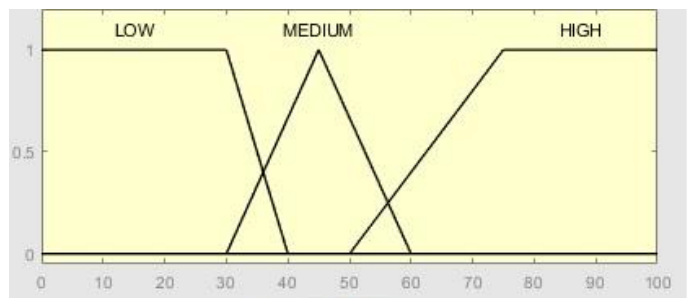

Figure 5: Membership Function for assignment feedback (K3)

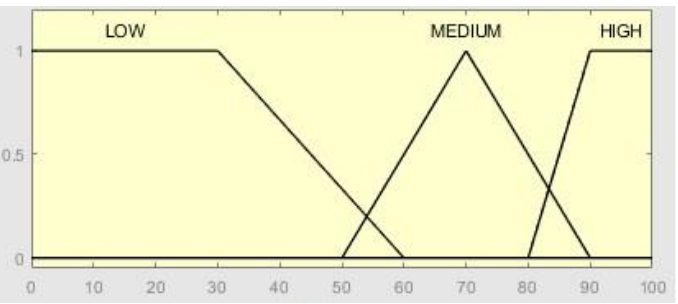

Figure 6: Membership Function for assignment score (K4)

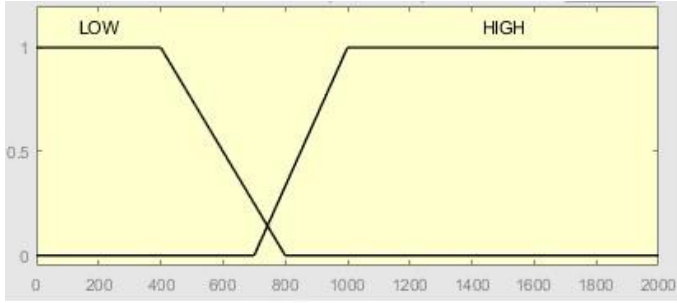

Figure 7: Membership Function for participation (K5)

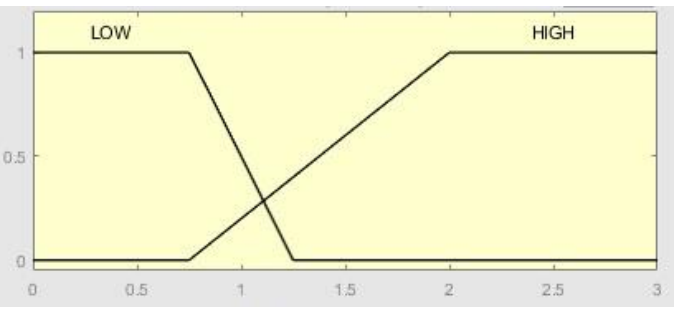

Figure 8: Membership Function for communication (K6)

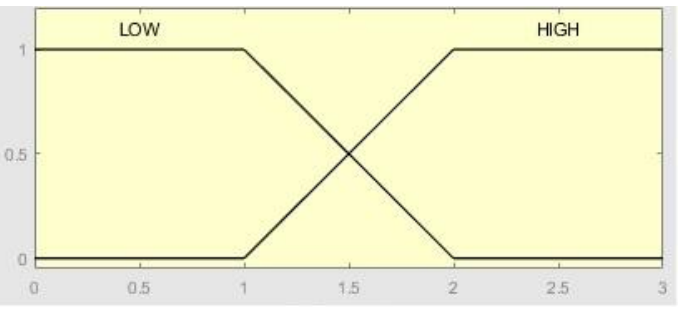

Figure 9: Membership Function for motivation (K7) 


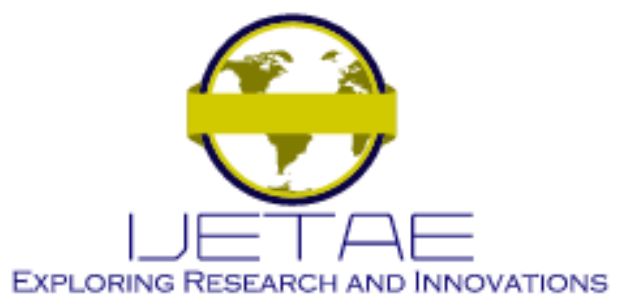

International Journal of Emerging Technology and Advanced Engineering

Website: www.ijetae.com (E-ISSN 2250-2459, Scopus Indexed, ISO 9001:2008 Certified Journal, Volume 11, Issue 09, September 2021)

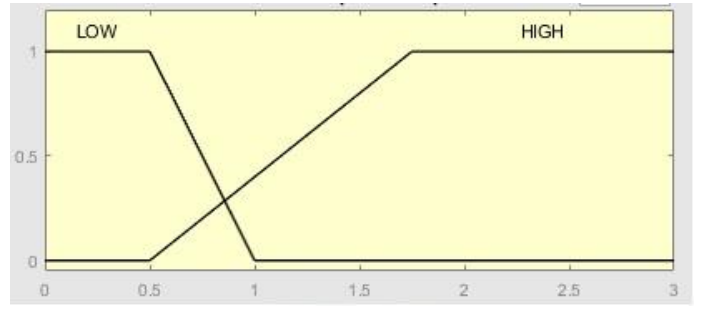

Figure 10: Membership Function for teaching style (K8)

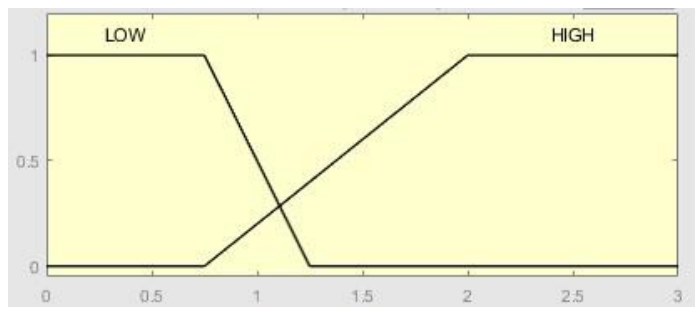

Figure 11: Membership Function for approach (K9)

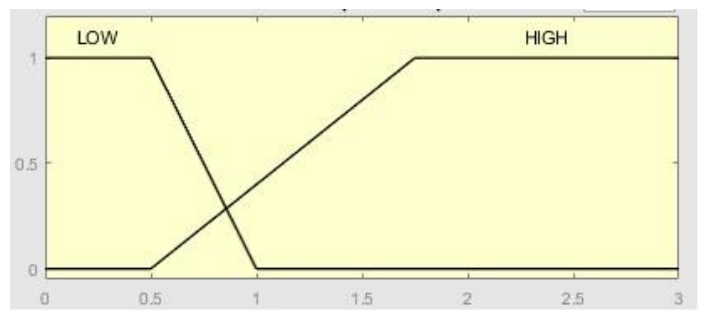

Figure 12: Membership Function for critical thinking (K10)

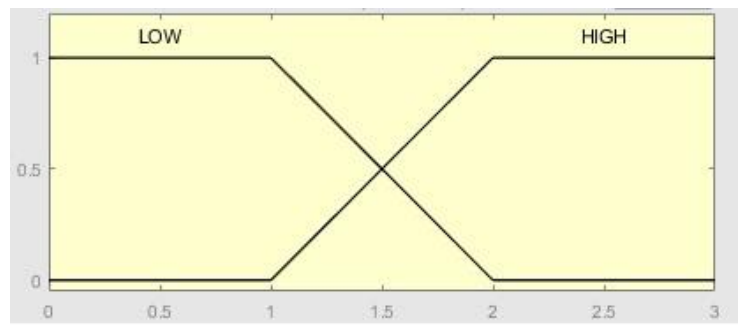

Figure 13: Membership Function for concern (K11)

Fuzzy rules are used for each parameter because each parameter has its own rules. Performance is viewed from each parameter. See TABLE 6. Here, only four parameters' rules are described as examples.
TABLE 6: FUZZY RULES FOR EACH PARAMETER

\begin{tabular}{|c|c|c|}
\hline \multirow[t]{5}{*}{ K1 } & Rule 1 & IF K1(LOW) THEN Performance(BAD) \\
\hline & Rule 2 & $\begin{array}{l}\text { IF } \quad \text { K1(LOW) AND } \quad \text { K1(MEDIUM) } \\
\text { THEN Performance(BAD) }\end{array}$ \\
\hline & Rule 3 & $\begin{array}{ll}\text { IF } \quad \text { K1(MEDIUM) } & \text { THEN } \\
\text { Performance(BAD) } & \end{array}$ \\
\hline & Rule 4 & $\begin{array}{l}\text { IF K1(MEDIUM) AND } \text { K1(HIGH) } \\
\text { THEN Performance(GOOD) }\end{array}$ \\
\hline & Rule 5 & $\begin{array}{ll}\text { IF } \quad \text { K1(HIGH) } & \text { THEN } \\
\text { Performance(GOOD) } & \end{array}$ \\
\hline \multirow[t]{5}{*}{$\mathrm{K} 2$} & Rule 1 & IF K2(LOW) THEN Performance(BAD) \\
\hline & Rule 2 & $\begin{array}{l}\text { IF } \quad \text { K2(LOW) AND } \text { K2(MEDIUM) } \\
\text { THEN Performance(BAD) }\end{array}$ \\
\hline & Rule 3 & $\begin{array}{l}\text { IF K2(MEDIUM) THEN Performance } \\
\text { (BAD) }\end{array}$ \\
\hline & Rule 4 & $\begin{array}{l}\text { IF K2(MEDIUM) AND } \text { K2(HIGH) } \\
\text { THEN Performance(GOOD) }\end{array}$ \\
\hline & Rule 5 & IF K2(HIGH) THEN Performance Good \\
\hline$\cdots$ & $\cdots$ & $\cdots$ \\
\hline \multirow[t]{3}{*}{ K10 } & Rule 1 & IF K10(LOW) THEN Performance Bad \\
\hline & Rule 2 & $\begin{array}{lrr}\text { IF K10(LOW) THEN } & \text { K10(HIGH) } \\
\text { THEN Performance Good } & \\
\end{array}$ \\
\hline & Rule 3 & $\begin{array}{lll}\text { IF K10(HIGN) } & \text { THEN } & \text { Performance } \\
\text { Good } & & \\
\end{array}$ \\
\hline \multirow[t]{3}{*}{ K11 } & Rule 1 & IF K11(LOW) THEN Performance Bad \\
\hline & Rule 2 & $\begin{array}{lrr}\text { IF } & \text { K11(LOW) THEN } & \text { K11(HIGH) } \\
\text { THEN Performance Good } & \\
\end{array}$ \\
\hline & Rule 3 & $\begin{array}{lll}\text { IF K11(HIGN) } & \text { THEN } & \text { Performance } \\
\text { Good } & & \\
\end{array}$ \\
\hline
\end{tabular}

C. Calculation of Performance Value and Final Result

To calculate the performance value of each class, it is calculated by multiplying the defuzzification value denoted by $Z i$ by the weight value of each parameter denoted by $W i$ and then adding up, which is mathematically written in equation (4). One tutor has a minimum of 1 class and a maximum of 4 classes; with the result that the calculated performance value is the performance value of each class.

$$
D V=\sum_{i=1}^{n} Z i * W i
$$

After getting the performance value of each class, the next step is to calculate the final result of all classes. Sum all performance values from each class and then calculate the average value, the overall performance score is earned. 


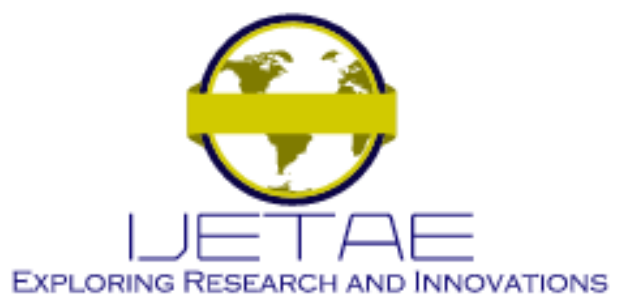

International Journal of Emerging Technology and Advanced Engineering

Website: www.ijetae.com (E-ISSN 2250-2459, Scopus Indexed, ISO 9001:2008 Certified Journal, Volume 11, Issue 09, September 2021)

The final result is then calculated. There were three final decisions, namely not continued, continued with training and continued without training. The final result has a membership function as shown in Figure 14. The final result also has a rule base, which can be seen in TABLE 7.

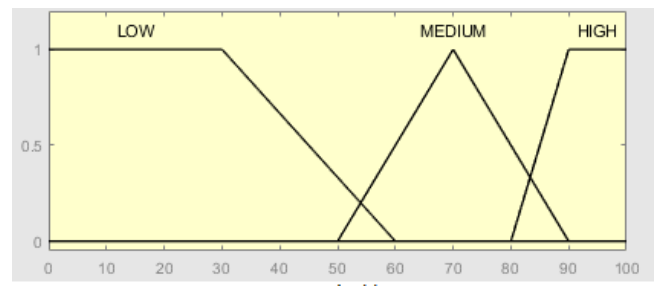

Figure 14: Membership Function for The Final Result

TABLE 7:

FUZZY RULES FOR THE FINAL RESULT

\begin{tabular}{|l|l|}
\hline Rule 1 & $\begin{array}{l}\text { IF The Final Result (LOW) THEN Not } \\
\text { Continued }\end{array}$ \\
\hline Rule 2 & $\begin{array}{l}\text { IF The Final Result (LOW) AND The } \\
\text { Final Result (MEDIUM) THEN Not } \\
\text { Continued }\end{array}$ \\
\hline Rule 3 & $\begin{array}{l}\text { IF The Final Result (MEDIUM) THEN } \\
\text { Continued with Training }\end{array}$ \\
\hline Rule 4 & $\begin{array}{l}\text { IF The Final Result (MEDIUM) AND The } \\
\text { Final Result (HIGH) THEN Continued } \\
\text { With Training }\end{array}$ \\
\hline Rule 5 & $\begin{array}{l}\text { IF The Final Result (HIGH) THEN } \\
\text { Continued Without Training }\end{array}$ \\
\hline
\end{tabular}

\section{Final Decision and Optimization}

The first activity is to perform pairwise comparisons for each parameter. Then calculate the $\mathrm{CR}$ value after the pairwise comparison matrix, which is found that the matrix is consistent. Furthermore, the weighting configuration is carried out to identify each weight value (W) of each parameter. The fuzzy rules used to calculate the performance value for each class taught by the tutor is the fuzzy rules for each parameter. By using a linear equation or constant DV, where the good performance criteria have an index value of 70 while the bad performance criteria have an index value of 50 .

From the sample obtained, the performance value for the entire class is calculated for each tutor, then to get the best value from each tutor, optimization needs to be done wherefrom eleven parameters only four parameters can be optimized to get the maximum value that can be obtained by the tutor. The four parameters are discussion feedback (K1), discussion score (K2), assignment feedback (K3), assignment score (K4).

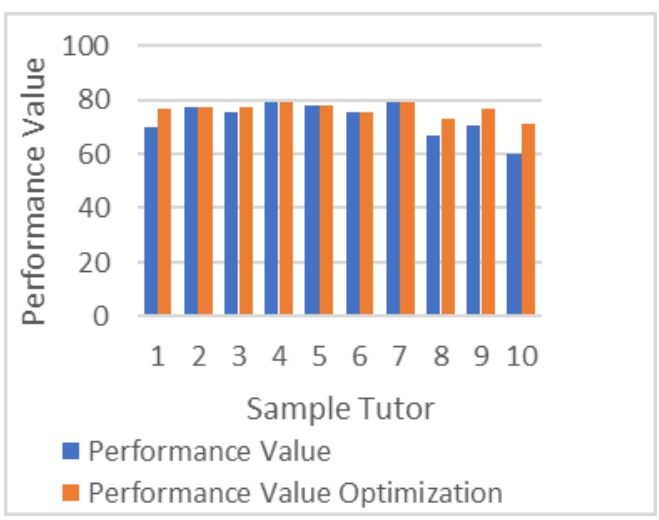

Figure 15: Optimization

In Figure 15 and TABLE 8 there is an increase in performance values, but if the four parameters have been maximized then after optimization the value will remain the same.

TABLE 8:

OPTIMIZATION

\begin{tabular}{|c|c|c|}
\hline Tutor & $\begin{array}{c}\text { Performance } \\
\text { Value }\end{array}$ & $\begin{array}{c}\text { Optimized } \\
\text { Performance Value }\end{array}$ \\
\hline 1 & 69.6 & 76.7 \\
\hline 2 & 77.1 & 77.3 \\
\hline 3 & 75.4 & 77.3 \\
\hline 4 & 78.9 & 78.9 \\
\hline 5 & 77.8 & 77.8 \\
\hline 6 & 75.4 & 75.4 \\
\hline 7 & 78.9 & 78.9 \\
\hline 8 & 66.6 & 73.2 \\
\hline 9 & 70.4 & 76.9 \\
\hline 10 & 59.9 & 70.9 \\
\hline
\end{tabular}

After getting the performance and then the final results are calculated for determining management decisions, namely not continued, continued with training, and continued without training, where the index value is 50 for "not continued", 70 for "continued with training", and 90 for "continued without training". An example of the calculation results is shown in Figure 16. For the final decision, the sample calculation results are shown in TABLE 9. 


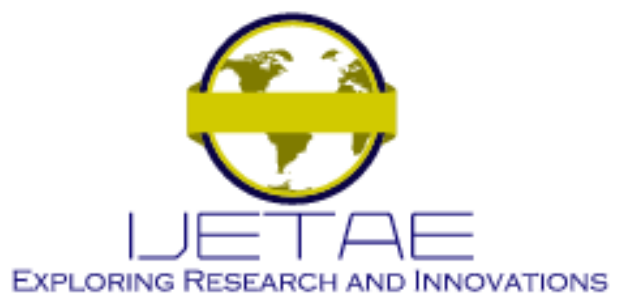

International Journal of Emerging Technology and Advanced Engineering

Website: www.ijetae.com (E-ISSN 2250-2459, Scopus Indexed, ISO 9001:2008 Certified Journal, Volume 11, Issue 09, September 2021)

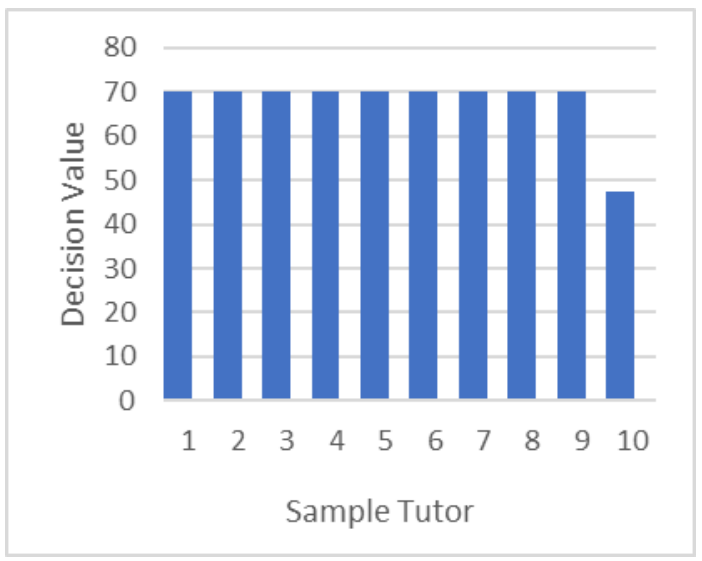

Figure 16: Result Value Decision

In the bar graph representing 10 cases, the data used, shows that the highest result is 70 , and the final decision "continued with training", and the lowest is 47.3 with the final decision "not continued".

TABLE 9: FINAL DECISION

\begin{tabular}{|c|c|l|}
\hline Tutor & $\begin{array}{c}\text { Decision } \\
\text { Value }\end{array}$ & \multicolumn{1}{|c|}{ Final Decision } \\
\hline 1 & 70.0 & Continued with Training \\
\hline 2 & 70.0 & Continued with Training \\
\hline 3 & 70.0 & Continued with Training \\
\hline 4 & 70.0 & Continued with Training \\
\hline 5 & 70.0 & Continued with Training \\
\hline 6 & 70.0 & Continued with Training \\
\hline 7 & 70.0 & Continued with Training \\
\hline 8 & 70.0 & Continued with Training \\
\hline 9 & 70.0 & Continued with Training \\
\hline 10 & 47.3 & Not Continued \\
\hline
\end{tabular}

Furthermore, the results of the performance value in optimization resulted in the decision value and final decision in TABLE 10 shows that tutor 10 which was originally "not continued" has increased to "continued with training".
TABLE 10: FINAL DECISION OPTIMIZATION

\begin{tabular}{|c|c|c|}
\hline Tutor & $\begin{array}{c}\text { Decision } \\
\text { Value } \\
\text { Optimization }\end{array}$ & $\begin{array}{c}\text { Final Decision } \\
\text { Optimization }\end{array}$ \\
\hline 1 & 70.0 & Continued with Training \\
\hline 2 & 70.0 & Continued with Training \\
\hline 3 & 70.0 & Continued with Training \\
\hline 4 & 70.0 & Continued with Training \\
\hline 5 & 70.0 & Continued with Training \\
\hline 6 & 70.0 & Continued with Training \\
\hline 7 & 70.0 & Continued with Training \\
\hline 8 & 70.0 & Continued with Training \\
\hline 9 & 70.0 & Continued with Training \\
\hline 10 & 70.0 & Continued with Training \\
\hline
\end{tabular}

\section{E. Discussion}

The results of the assessment that we built can be a solution for institutions in monitoring the performance of tutors who teach with Moodle. Institutions can also use it to evaluate whether the training provided is effective enough to improve tutor performance in online teaching; where monitoring tutors in online teaching is rather difficult, unlike the face-to-face teaching process, which can directly see the process. In addition, it can also be used as material for evaluating the next strategy for institutions in terms of improving the quality of teaching.

Of the eleven parameters only four parameters can be optimized. The four parameters are discussion feedback (K1), discussion score (K2), assignment feedback (K3), assignment score (K4). For participation parameters (K5) do not have the maximum value, communication parameters (K6), motivation (K7), teaching style (K8), approach (K9), critical thinking (K10), and concern (K11) are obtained from questionnaires filled out by students.

There are weaknesses in the assessment by taking log data from the Moodle, the value taken is the number of logs, it is not known whether the feedback, both discussion feedback and assignments have been given properly. A tutor can give feedback on assignments to all students who submit assignments, but the feedback used can only be a thank you and not feedback related to student assignments. 


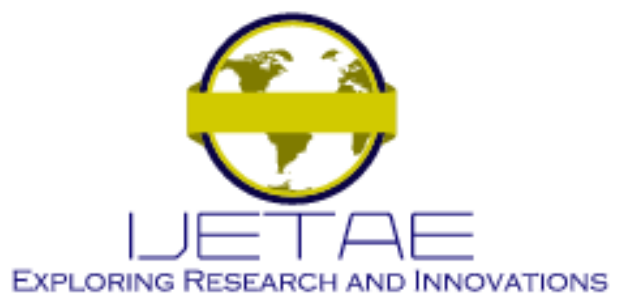

International Journal of Emerging Technology and Advanced Engineering

Website: www.ijetae.com (E-ISSN 2250-2459, Scopus Indexed, ISO 9001:2008 Certified Journal, Volume 11, Issue 09, September 2021)

\section{CONCLUSION}

DSM for tutor performance evaluation has been successfully built. The model uses fuzzy AHP. The performance appraisal process is carried out using eleven relevant parameters based on previous research and also based on the needs of the institution. The data used were taken randomly from four faculties, namely the faculty of teacher training, the faculty of social sciences, the faculty of economics and the faculty of science. The data is taken from the Moodle log, where one tutor can teach at least one class and a maximum of four classes with a maximum of fifty students. In addition to data from the logs, there is also data from the questionnaire results contained in each class. Students fill out the questionnaire related to the student's assessment of their tutor.

The results of this model can be used by institutions in terms of improving the quality of tutors who teach online and as an evaluation material for the implementation of training for tutors, which is in accordance with the purpose of a decision [20].

\section{REFERENCES}

[1] Rumanta, M. (2018). Effectiveness of Online Learning Tutorials Viewed from the Students Perspective: Case Study on Biology Education Program of Universitas Terbuka. Advanced Science Letters, 24(11), 8418-8421. doi:10.1166/asl.2018.12578

[2] Zuhairi, A., Adnan, I. \& Thaib, D. (2007). Provision of student learning support services in a largescale distance education system at an open university, Indonesia. The Turkish Online Journal of Distance Education, 8(4), 44-64.

[3] Rahardjo, Djoko. (2018). E-Learning Readiness and Tehnology Adoption in Online Tutorial. Conference: The 32nd Annual Conference of the Asian Association of Open Universities (AAOU) 2018. Hanoi, Vietnam.

[4] Utama, D. N., \& Rustamaji, E. (2018). Fuzzy Decision Support Model for Human Resources Performance Appraisal. 2018 International Conference on Information Management and Technology (ICIMTech). doi: 10.1109/icimtech.2018.8528145

[5] Marsiningsih, R. Madhakomala, \& K. Gunawan (2019). Decision Support System Of Performance Appraisal Policy Continuity In The Logistic Staff Of Indonesian Armed Force Using Discrepancy Evaluation Model And Analytical Hierarchy Process. (2019). International Journal of Recent Technology and Engineering 2, 8(2), 5372-5380. doi: 10.35940/ijrte.b3166.078219
[6] Gunawan, F., Wang, G., Utama, D. N., Komsiyah, S., \& Suharjito. (2018). Decision Support Model for Supplier Selection Using Fuzzy Logic Concept. 2018 International Conference on Information Management and Technology (ICIMTech). doi: 10.1109/icimtech.2018.8528103

[7] Moodle Statistics. (2020). Retrieved April 19, 2020, from https://moodle.net/stats/

[8] Open University. Retrieved December 14, 2019 from https://id.wikipedia.org/wiki/Universitas_Terbuka

[9] Berge, Z.L(1995). The Role of the Online Instructor/Facilitator. Facilitating Computer Conferencing: Recommendations From the Field. Educational Technology. 35(1) 22-30

[10] Jelfs, A., Richardson, J. T., \& Price, L. (2009). Student and tutor perceptions of effective tutoring in distance education. Distance Education, 30(3), 419-441. doi: 10.1080/01587910903236551

[11] Kahu, E. R., \& Picton, C. (2019). The benefits of good tutor-student relationships in the first year. Student Success, 10(2), 23-33. doi: 10.5204/ssj.v10i2.1293

[12] Kara, M., \& Can, G. (2019). Master's Students' Perceptions and Expectations of Good Tutors and Advisors in Distance Education. The International Review of Research in Open and Distributed Learning, 20(2). doi: 10.19173/irrodl.v20i2.3674

[13] Kusmawan, Udan. (2009). Student perception on Open University Online Learning Tutorial (UT-OLT). Conference: AAOU ( Asian Association of Open Universities ) Conference 2009.

[14] McPherson, M \& Nunes, M.B (2004). The Roles of Tutors as an Integrated Part of Online Learning. Third EDEN Research Workshop, Oldenburg, Germany.

[15] Yildiz, Z., \& Baba, A. F. (2014). Evaluation of student performance in laboratory applications using fuzzy decision support system model. 2014 IEEE Global Engineering Education Conference (EDUCON). doi: 10.1109/educon.2014.6826230

[16] Ramadhan, G \& Utama, D. (2019). Fuzzy Tsukamoto based Decision Support Model for Purchase Decision in Pharmacy Company. International Journal of Recent Technology and Engineering. 8. 10.35940/ijrte. D8243.118419.

[17] Akcay, C., \& Manisali, E. (2018). Fuzzy decision support model for the selection of contractor in construction works. Fuzzy Decision Support Model for the Selection of Contractor in Construction Works, 258-266. doi: 10.7764/rdlc.17.2.258

[18] Utama, D. N. (2017). Sistem Penunjang Keputusan, Filosofi Teori dan Implementasi. Yogyakarta, Indonesia: Garudawacha.

[19] Wasira, Wambura. (2020). Formal Verification Methods. 10.1007/3540-. Retrieved May 2020 from https://www.researchgate.net/publication/339399690_Formal_Verifi cation_Methods

[20] Hasan, M.Iqbal. (2002). Pokok-pokok materi pengambilan keputusan. Jakarta : Penerbit Ghalia Indonesia. 